\title{
Using Climate Predictions in Great Lakes Hydrologic Forecasts
}

\author{
T. E. Croley II ${ }^{1}$ \\ ${ }^{1}$ Great Lakes Environmental Research Laboratory, National Oceanic and \\ Atmospheric Administration, U.S. Department of Commerce, 2205 Commonwealth \\ Blvd., Ann Arbor, Michigan 48105-2945
}

\begin{abstract}
The Great Lakes Environmental Research Laboratory's (GLERL's) Advanced Hydrologic Prediction System (AHPS) illustrates the technology for those interested in using climate predictions in water resources decisions. It provides $1-6$-month probability outlooks for 25 hydrology variables over the 121 watersheds and 7 lake surfaces of the Great Lakes basin, including simultaneous water levels on all lakes. The system incorporates both current conditions, antecedent to a forecast, and multiagency, multi-area, multi-period climate outlooks of meteorology probabilities. Extended water level forecasts are evaluated over three periods to determine the value of antecedent conditions and meteorological outlooks in making them. The suitability of GLERL's AHPS forecasts is also considered relative to existing US and Canadian forecasts. While the use of antecedent conditions adds considerably to Great Lakes forecasting ability, the use of existing meteorological outlooks adds little. GLERL's AHPS appears better than, or as good as, other Great Lakes forecasts and offers the advantage of improvement as better near real time data streams and improved process models become available. Forecasts that utilize climate predictions are used in several water resource decision settings, as illustrated here.
\end{abstract}

\section{BACKGROUND}

The Laurentian Great Lakes are located in North America (Figure 1). Extreme Great Lakes water levels cause extensive flooding, erosion, and damage to shorelines, shipping, and hydropower. Knowledge of even near-normal level expectations is important to riparians, recreational users, shipping, fishing, and many others. The International Joint Commission, at the request of the US and Canadian governments, recommended improving forecast methodologies, hydrological models, data collection, and communication of hydrological forecast information (IJC 1993). While forecasts of meteorology, riverine flooding, and water level fluctuations are available for several hours to several days, the Great Lakes community requires water resource forecasts over large areas and time periods. Products must include nowcasts and 1-day to 6-month future seasonal probabilistic outlooks of lake supplies, lake levels, and connecting channel flows. These require careful tracking of moisture storage variables and heat storage variables. The products must be relevant to users 


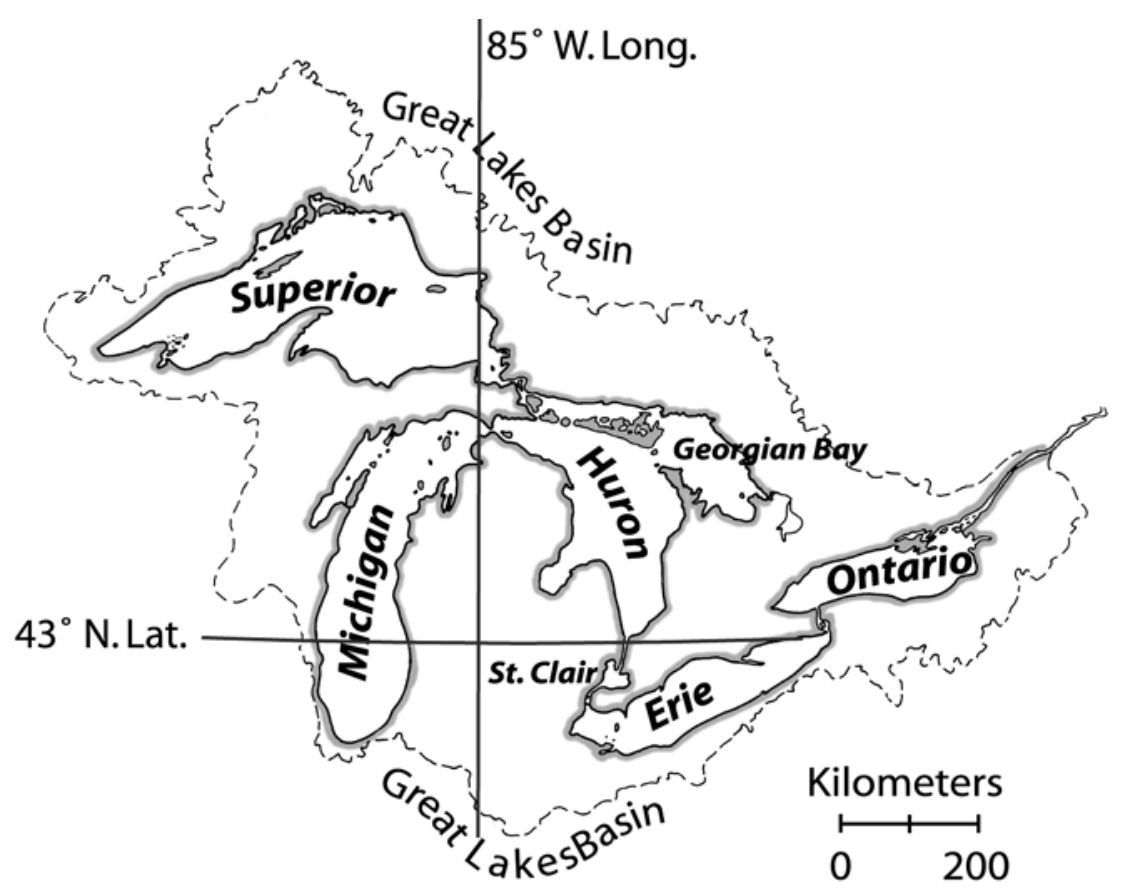

Figure 1. Laurentian Great Lakes and Basin.

and delivered in a clear and understandable manner that aids in planning and decision-making. They must make maximum use of all available information and be based on efficient and realistic hydrological process models.

This paper first looks at climate effects on Great Lakes levels and reviews recent Great Lakes levels forecasting history. It describes the Great Lakes Advanced Hydrologic Prediction System (AHPS) built by the Great Lakes Environmental Research Laboratory (GLERL), including use of probabilistic meteorological outlooks. The paper then determines the value of considering antecedent conditions and (separately) the value of considering probabilistic meteorological outlooks in making hydrological outlooks for the Great Lakes. Also, the paper considers the suitability of GLERL's AHPS forecasts in making probabilistic outlooks of Great Lakes water levels relative to other existing methods. Finally, the paper discusses the forecasting system utility to decision makers and potential impacts in practical applications.

\section{CLIMATE EFFECTS ON GREAT LAKES LEVELS}

There are three primary types of lake level fluctuations: long-term lake levels (represented on an annual basis), seasonal lake levels, and short-period lake level changes due to wind setup and storm surge. Annual fluctuations result in most of the variability leading to the record high and low lake levels. There is an overall range of about $2 \mathrm{~m}$ (6 ft) in the annual levels. Precipitation causes the major long-term variations in lake levels (Quinn and Croley 1981; Quinn 1985). Table 1 shows that annual precipitation ranges from about $82 \mathrm{~cm}$ (32 in) for Superior to $93 \mathrm{~cm}$ (37 in) for Ontario. Annual precipitation correlates very well with annual lake levels as observed by superimposing the annual precipitation on the annual Lake Erie water 
Table 1. Partial Great Lakes Annual Water Balance (1951-1988).

\begin{tabular}{|c|c|c|c|c|c|c|c|c|c|c|}
\hline \multirow[t]{2}{*}{ Component } & \multicolumn{2}{|c|}{ Superior } & \multicolumn{2}{|c|}{ Michigan } & \multicolumn{2}{|c|}{ Huron } & \multicolumn{2}{|c|}{ Erie } & \multicolumn{2}{|c|}{ Ontario } \\
\hline & $(\mathrm{cm})$ & (in) & $(\mathrm{cm})$ & (in) & $(\mathrm{cm})$ & (in) & $(\mathrm{cm})$ & (in) & (cm) & (in) \\
\hline & 82 & 32 & 83 & 32 & 87 & 34 & 81 & 36 & 93 & 37 \\
\hline & 62 & 24 & 64 & 25 & 84 & 33 & 80 & 32 & 169 & 67 \\
\hline Lake Evaporation & 56 & 22 & 65 & 25 & 63 & 25 & 90 & 35 & 67 & 26 \\
\hline
\end{tabular}

${ }^{a}$ Equivalent depth over the lake area.

levels in Figure 2. The precipitation tends to lead the water levels by approximately one year, as shown here by the 1929 highs, the 1935 lows, the 1952 highs, and the 1963 lows. In particular, the high precipitation of 1970-1985 resulted in very high water levels. Variations in air temperature also influence lake level fluctuations. At higher air temperatures, plants tend to use more water, resulting in more transpiration, and there are higher rates of evaporation from both the ground surface and the lake. This yields less runoff for the same amount of precipitation than would exist during a low temperature period when there is less evaporation and transpiration. Coupled with the higher lake evaporation, lake levels drop with increasing air temperature, all other things being equal. The annual mean air temperature around the perimeter of the Great Lakes shows three distinct temperature regimes: a low temperature regime from 1900-1929, a higher temperature regime from about 1930-1959, and an additional low regime from 1960-1990 period. Thus, the high levels of 1970-1985 are the result of both the increased precipitation regime since 1940 coupled with the lower temperature regime since 1960 .

Superimposed on the annual levels are the seasonal cycles; each lake undergoes a seasonal cycle every year. The magnitude depends upon the individual

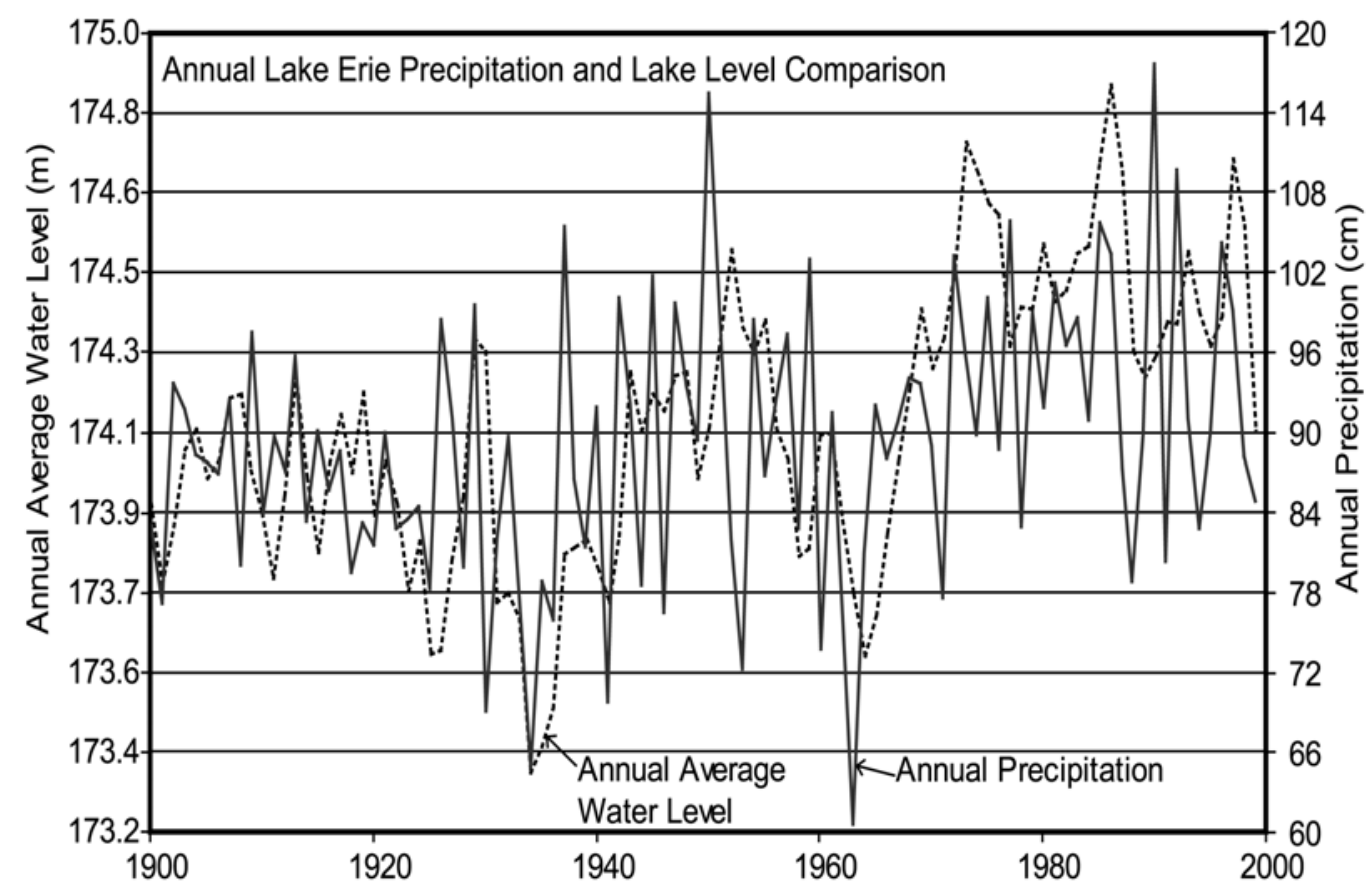

Figure 2. Annual Lake Erie Levels and Precipitation. 


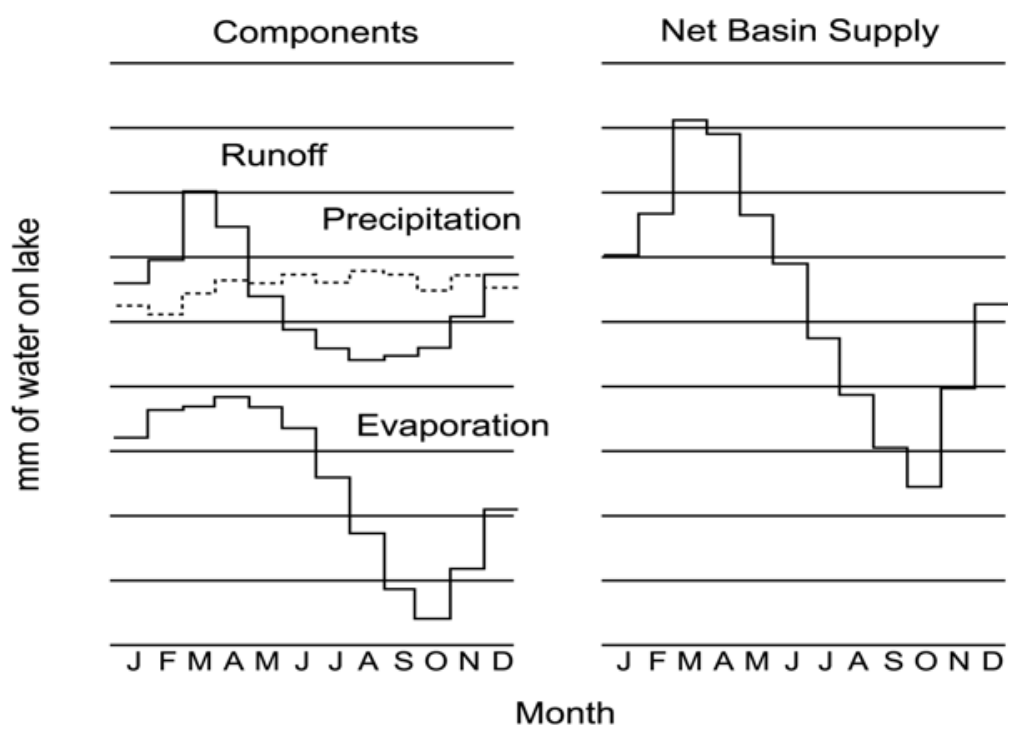

Figure 3. Seasonal Erie Basin Supplies.

water supplies. The range varies from about $30 \mathrm{~cm}(1 \mathrm{ft})$ on the upper lakes to about $38 \mathrm{~cm}(1.3 \mathrm{ft})$ on the lower lakes. In general, the seasonal cycles have a minimum in the winter, usually January or February. The levels then rise due to increasing water supplies from snow melt and spring precipitation until they reach a maximum in June for the smaller lakes, Erie and Ontario, and September in the case of Lake Superior. When the net basin supplies diminish in the summer and fall, the lakes begin their seasonal decline. The magnitude of the net basin supply components varies with season, as shown in Figure 3 for Lake Erie (Quinn 1982; Quinn and Kelley 1983). The monthly precipitation is fairly uniformly distributed throughout the year, while the runoff has a peak during the spring which results primarily from the spring snow melt. The runoff is at a minimum in the late summer and early fall due to large evapotranspiration from the land basin. The lake evaporation reaches a minimum during the spring and gradually increases until it reaches a maximum in the late fall or early winter. The high evaporation period is due to very cold dry air passing over warm lake surfaces. The integration of these components is depicted in the net basin supply, which consists of the precipitation plus the runoff minus the evaporation. As seen from Table 1, these three components of net basin supply are all of the same order of magnitude for each lake. Annual runoff to the lake ranges from about $62 \mathrm{~cm}$ (24 in) for Superior to $169 \mathrm{~cm}$ (67 in) for Ontario, and annual lake evaporation ranges from about $56 \mathrm{~cm}$ (22 in) for Superior to $90 \mathrm{~cm}$ ( $35 \mathrm{in}$ ) for Erie. The net basin supply is seen in Figure 3 to reach a maximum in April and a minimum in the late fall. The negative values indicate that more water is leaving the lake through evaporation than is being provided by precipitation and runoff.

The final type of fluctuation, common along the shallower areas of the Great Lakes, particularly Lake Erie, Saginaw Bay, and in some cases on Green Bay, are storm surges and wind set-up. When the wind is blowing along the long axis of a shallow lake or bay, a rapid difference in levels can build over the water. This difference can be as large as $5 \mathrm{~m}$ (16 ft) for Lake Erie (storm of 2 December 1985). 
These storm conditions, when superimposed on high lake levels, cause most of the Great Lakes shoreline damage.

\section{HISTORY}

Forecasting efforts in the Great Lakes include the former US Lake Survey of the US Army Corps of Engineers, which began 6-month lake level forecasts in 1952. Since 1975, the Detroit District of the Corps has continued lake level forecasting on a monthly basis. The Canadian Hydrographic Service (CHS) of the Department of Fisheries and Oceans began publishing monthly forecasts of levels in 1973. The Canadian forecasts are generated currently by the Great Lakes - St. Lawrence Regulation Office of Environment Canada and published by the CHS. Both the US and Canadian monthly forecasts project water levels for each of the Great Lakes six months into the future. These forecasts are generated separately by each agency and then are coordinated to remove any differences. The Corps deterministic forecast is based upon extrapolations of recent trends in water supplies for each of the lakes. Environment Canada's probabilistic forecast is computed from statistical analysis of historical water supplies. Neither agency uses weather forecasts or antecedent hydrological conditions (current moisture and heat storages in the basins and lakes) in making their outlooks.

GLERL adapted runoff models to estimate supplies in 1982, identified weak evaporation estimates in 1985, added improved one-dimensional evaporation models in 1990, altered deterministic outlooks, added probabilistic outlooks, and identified meteorological outlooks as the weakest component in 1993. In 1995, they defined AHPS for the Great Lakes, incorporating NOAA meteorological outlook probabilities available only since the start of that year. From 1996 through 1998 they expanded AHPS to use mixed meteorological outlook event probabilities and most-probable events and in 1999 they added new ways of combining these meteorological outlooks in making derivative hydrological outlooks. In 2002, they added parametric consideration of meteorological outlook probabilities to their non-parametric techniques. GLERL installed their forecast package for the US Army Corps of Engineers in three offices, for the New York Power Authority and Ontario Hydro, for

the Midwest Climate Center, and Environment Canada. Both the Corps and Environment Canada are now using AHPS in an evaluation mode.

\section{GREAT LAKES AHPS}

GLERL developed, calibrated, and verified conceptual model-based techniques for simulating hydrological processes in the Laurentian Great Lakes (including Georgian Bay and Lake St. Clair, both as separate entities). GLERL integrated the models into a system to estimate lake levels, whole-lake heat storage, and water and energy balances (Croley et al. 1996). These include models for rainfall-runoff, evapotranspiration, and basin moisture storage [121 daily watershed models (Croley 2002)], overlake precipitation (a daily estimation model), one-dimensional (depth) lake thermodynamics [7 daily models for lake surface flux, thermal structure, evaporation, and heat storage (Croley 1989, 1992; Croley and Assel 1994)], net lake 
supplies, channel routing [4 daily models for connecting channel flows and levels, outlet works, and lake levels (Hartmann 1988; Quinn 1978)], lake regulation [a monthly plan balancing Lakes Superior, Michigan, and Huron and a quarter-monthly plan balancing Lake Ontario and the St. Lawrence Seaway (International St. Lawrence River Board of Control 1963)], and diversions and consumption (International Great Lakes Diversions and Consumptive Uses Study Board 1981). The modeling system is modularly built, allowing model upgrades to be "dropped in" as developed and tested.

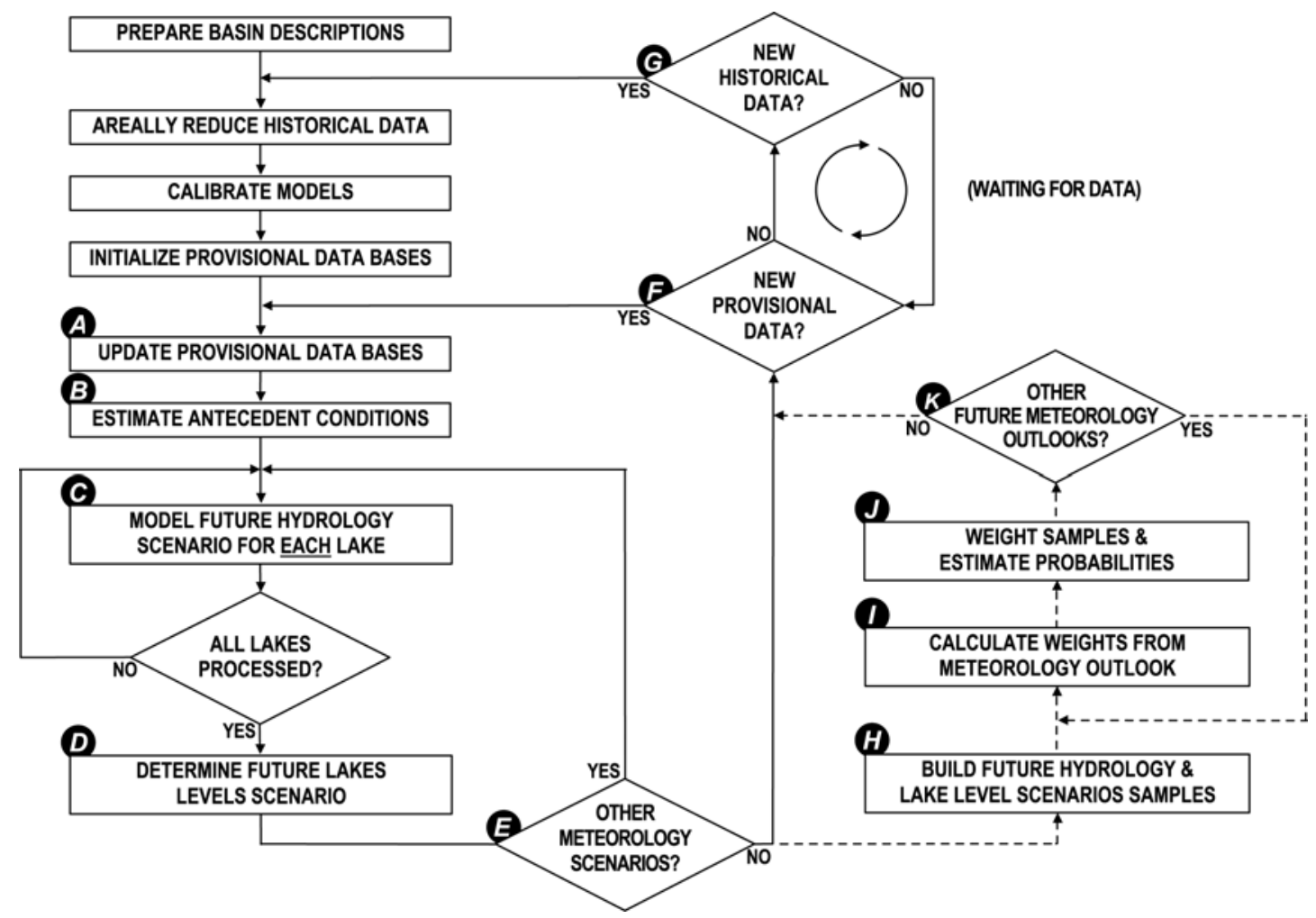

Figure 4. Overview of Great Lakes Advanced Hydrologic Prediction System.

Deterministic Hydrology Forecasts. GLERL first developed a deterministic forecast as a semiautomatic software package. It integrates modeling and near real-time data handling and reduction to enable representation of current system states and simulated futures. Figure 4 (excluding the dashed-line portion) shows deterministic forecasts. Inputs are daily meteorology (air temperature, dew point temperature, precipitation, wind speed, and cloud cover) for all available stations. Optional inputs are snow water equivalent, soil moisture, lake water temperature, and lake levels. GLERL converts daily provisional point data into areal averages for each watershed and lake surface by Thiessen weighting over digital maps of the areas (Croley and Hartmann 1985) (A in Figure 4). GLERL's runoff model (applied to each Great Lakes watersheds) and their lake thermodynamics model (applied to each lake) use the areal averages to estimate basin moisture and lake heat as antecedent (initial) conditions to a forecast (B in Figure 4). A deterministic "forecast" of all hydrology variables, including lake supply, may be made then by simulating the hydrology from 
the point of estimated initial conditions forward with a meteorology scenario (taken from the historical record, for example) ( $\mathrm{C}$ in Figure 4). The resulting lake supply scenarios, one for each lake, then are used with connecting-channel routing and lake regulation models to determine a lake levels scenario ( $D$ in Figure 4). This can be repeated for alternate meteorology scenarios (E in Figure 4). New provisional data are used as they become available (F in Figure 4); new historical data are also used as available to update models and databases ( $\mathrm{G}$ in Figure 4).

Probabilistic Hydrology Forecasts. GLERL adapted this deterministic forecasting methodology to make probabilistic forecasts by considering historical meteorology as possibilities for the future. An operational hydrology approach (used also by the National Weather Service in their Ensemble Streamflow Prediction forecasts) segments the historical record and uses each segment with models to simulate a possible "scenario" for the future. Sections of the historical meteorology record are input to hydrological, limnological, and other models, as in E in Figure 4, as alternate meteorology scenarios, preserving observed spatial and temporal interrelationships. Corresponding hydrology variable scenarios are computed for the future, including lake supply scenarios. The resulting set of scenarios serves as a statistical sample for inferring probabilities and other parameters associated with both meteorology and hydrology (Figure 5, excluding "Meteorology Forecast Weighting," and H in Figure 4). Probabilistic hydrology outlooks then are made from the sample for each variable of interest. Thus, the resulting probabilistic hydrology outlooks properly consider antecedent hydrological conditions, but they do not consider predictions of meteorology.

Probabilistic Meteorology Outlooks. Multiple long-lead probabilistic meteorology outlooks of improving skill (climate outlooks) are now available to forecasters. These outlooks are defined over different time periods at different time lags; they forecast either event probabilities or most-probable events. The National Oceanic and Atmospheric Administration's (NOAA's) Climate Prediction Center (CPC) changed in January 1995 from issuing a few relatively short-term outlooks of meteorology probabilities to a new multiple long-lead "climatic outlook." The outlook consists of a 1-month forecast for the next (full) month and thirteen 3-month forecasts, going into the future in overlapping fashion in 1-month steps. Each forecast predicts probabilities of average air temperature and total precipitation falling within selected intervals. The CPC since has begun issuing other outlooks (including 1-, 2-, 3-, and 5-day outlooks, 6-10-day outlooks, and second-week outlooks). Likewise, the Atmospheric Environment Service's Canadian Meteorological Center (CMC) of Environment Canada began issuing an outlook of the most probable interval for 30-day air temperature every half month (24 times per year). The CMC also issues outlooks quarterly of the most probable intervals for 90day air temperature and precipitation and three experimental outlooks of the most probable intervals for 90-day air temperature and precipitation, going into the future in 3-month steps. New outlooks are appearing, including NOAA National Center for Environmental Prediction's ensemble forecasts. 


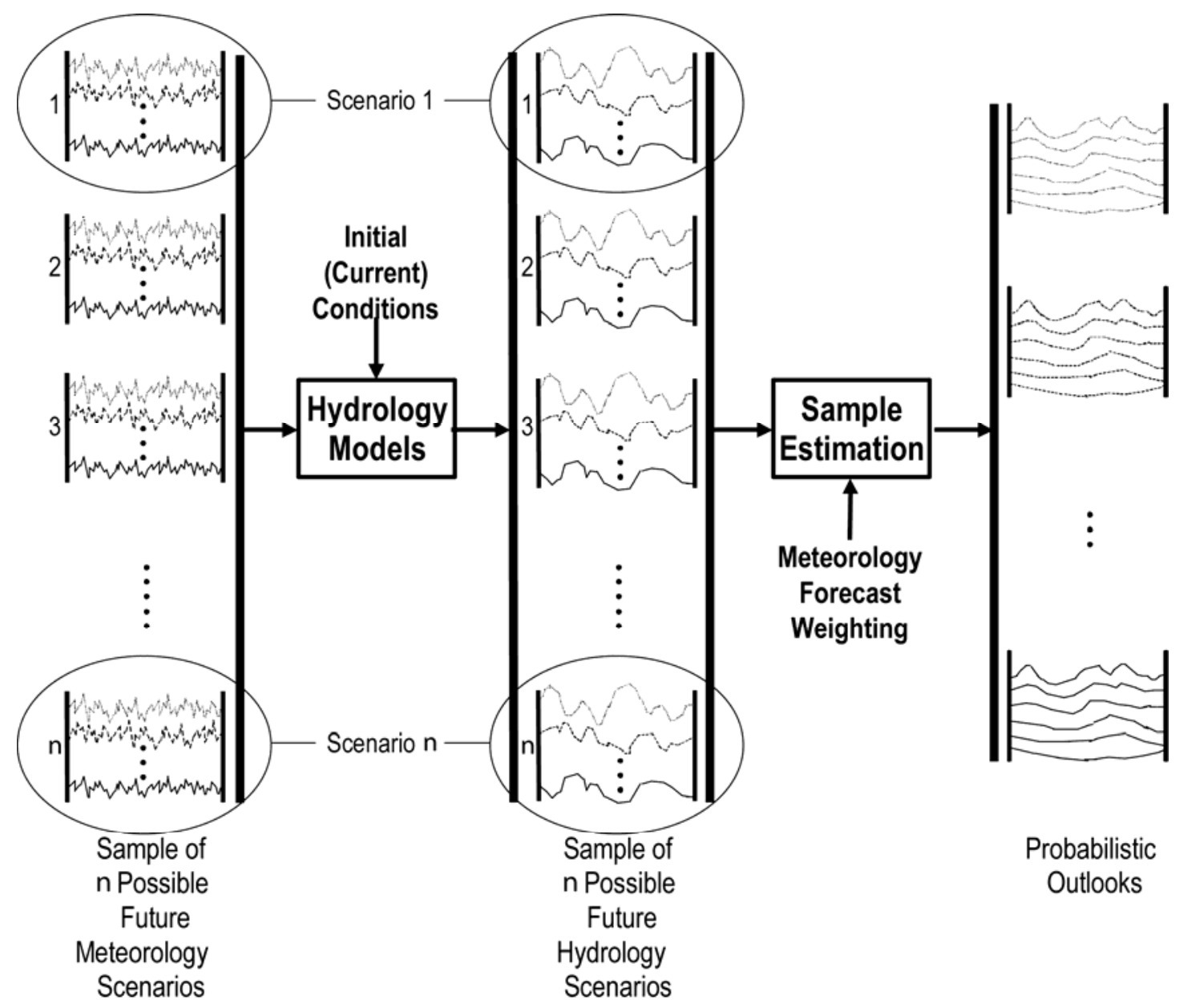

Figure 5. Operational Hydrology Schematic.

Calculation of Weights. Users can interpret these probabilistic meteorology outlooks to improve their probabilistic hydrology outlooks. Relative frequencies of selected events (in the statistical sample of scenarios used in the operational hydrology approach in $\mathrm{H}$ in Figure 4 and in Figure 5) are fixed at historical values that are incompatible (generally) with the CPC's or CMC's probabilistic meteorology outlooks. Only by restructuring the set of scenarios can one obtain relative frequencies of selected events for a lake that match the CPC and CMC probabilistic meteorology outlooks over the lake. Recently, GLERL incorporated multi-agency, multi-period forecasts of meteorology probabilities by modifying their operational hydrology approach to generate probabilistic hydrology outlooks compatible with the meteorology outlooks. Croley (2000) introduced a method that weights the scenarios and identifies equations for the weights that correspond to probabilistic meteorology outlooks (I in Figure 4). The hydrology variable scenarios, generated from corresponding historical meteorology record segments, are still used as a statistical sample for inferring probabilities, but the sample is first restructured by weighting ( $\mathrm{J}$ in Figure 4).

The solution may involve an optimization, when there is more than one set of weights possible, and therefore may require an objective function to select between 
various solutions. Since all equations may not be satisfied simultaneously, they are ordered in priority and as many as possible are used (the lowest-priority equations are discarded). More weight is given to sample scenarios whose corresponding historical meteorological record segments contain events appropriate to the meteorological forecasts. For example, more weight is given to those six-month lake level scenarios corresponding to monthly air temperatures in the upper third of their range when the meteorological outlook calls for above-normal monthly air temperatures; the value of the weight depends on the probabilities specified in the meteorological outlook. GLERL's AHPS weights the sample of lake level scenarios each month to agree with these equations and then estimates outlook probabilities from the weighted sample (Croley 2000) (J in Figure 4). Now probabilistic hydrology outlooks consider both antecedent hydrological conditions and predictions of meteorology (Figure 5).

Simultaneous Spatial Outlooks. The probabilistic outlook of lake levels involves an additional complication. In a deterministic forecast, the forecast lake supply scenarios for each and all of the Great Lakes can be used as inputs to the connectingchannel routing and lake regulation models to determine the (simultaneous) lake level forecast scenarios on each lake. The connecting-channel routing and lake regulation models require water supplies on all lakes simultaneously to determine levels and outflows jointly on all lakes because all levels and outflows are interdependent. In a probabilistic outlook, the direct application of such a methodology might not be suitable for two reasons. 1) One cannot simply take the (say) $95^{\text {th }}$ exceedance time series for water supplies as input to the connecting-channel routing and lake regulation models to determine the $95^{\text {th }}$ exceedance time series for lake levels or outflows. There is not a simple one-to-one transform between quantiles of water supplies and lake levels. It is more appropriate to use the entire sample of water supply scenarios to create a sample of lake level scenarios from which to make probability outlooks. 2) However, since each lake (application area) involves a (generally) different set of probabilistic meteorology outlooks and set of weights, the water supply scenarios do not correspond to the same statistical sample from lake to lake. The use of all of the water supply scenarios for all of the Great Lakes, derived independently, as simultaneous inputs to the connecting-channel routing and lake regulation models then would not be representative of the same statistical sample when calculating lake level scenario forecasts.

An appropriate method for determining joint lake level probabilities simultaneously solves all sets of equations (for the meteorological outlook weights over all application areas) to determine one set of weights that preserves all meteorology outlooks. The resulting weights are used directly in the solution for lake level probabilities, where the sample of lake level scenarios is derived from the appropriate simultaneous water supply scenarios on all the lakes (Figure 4). Note also that, in Figure 4, alternate meteorology outlooks (forecasts) may be considered without having to repeat provisional data updates, estimates of antecedent conditions, or any of the hydrology modeling required in sample building ( $\mathrm{K}$ in Figure 4). 


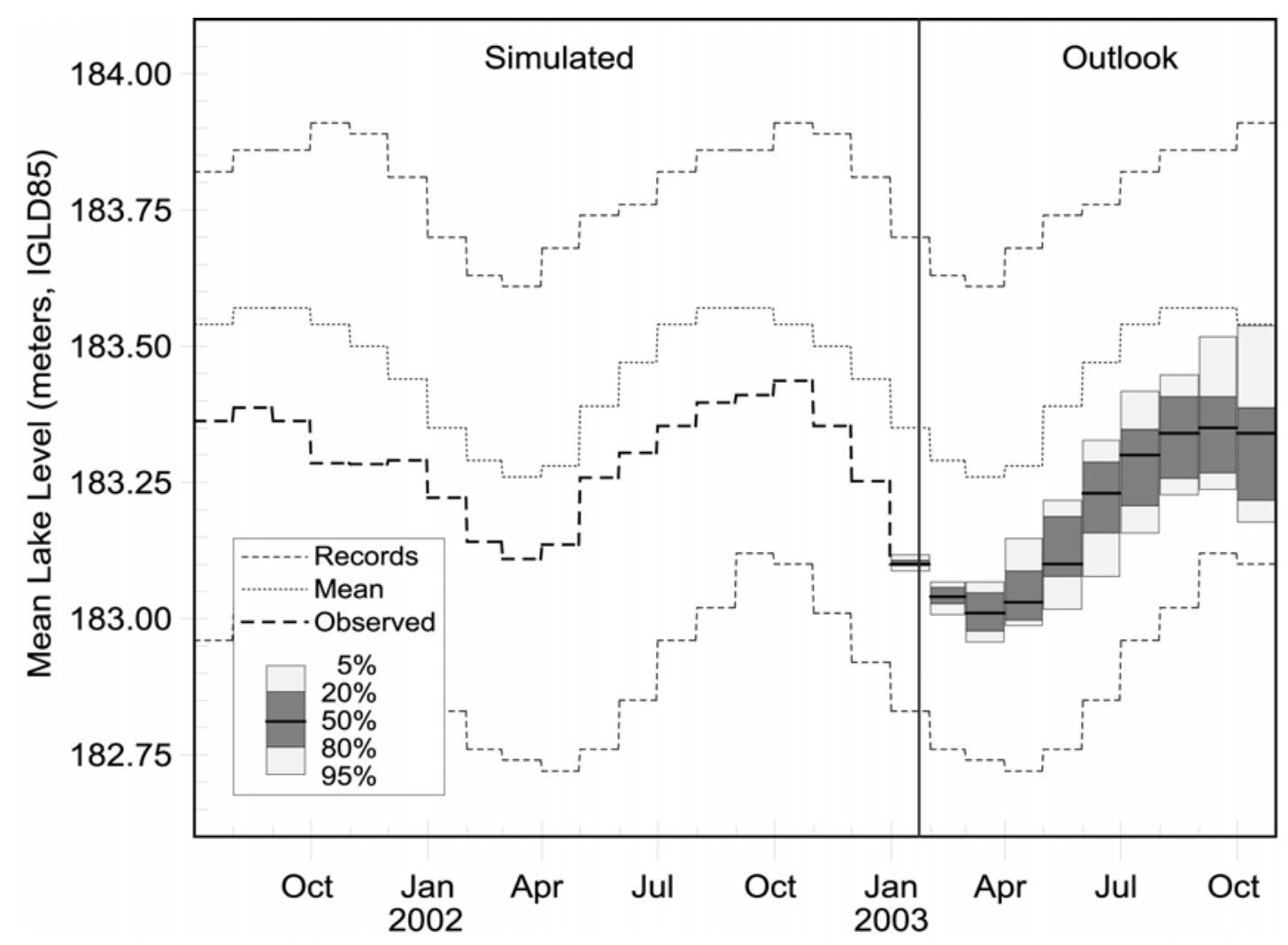

Figure 6. January 23, 2003 Probabilistic Superior Level Exceedance Outlook.

Figure 6 shows an example probabilistic lake level outlook. It is based on probabilistic meteorology outlooks from NOAA and Environment Canada from December 2002 when they both predicted above-normal air temperature probabilities and below-normal precipitation probabilities for December 2002-May 2003. The methodology provides an objective and open-ended means of matching forecast meteorology probabilities in other forecasts besides the water resource forecasts considered here. This illustrates jointly considering multiple forecasts over multiple areas for multiple (different simultaneous) periods as they become available in the future.

\section{GREAT LAKES AHPS EVALUATION}

Evaluation Methodology. GLERL simulated probabilistic lake level outlooks for 1995-August 1997 with three "operational hydrology" methods. Firstly, GLERL assembled all six-month net basin supply (NBS) time series from the historical record (1954-1997) that started the same month as each month of the period 1995-August 1997 into a sample for that month, from which to estimate a six-month forecast beginning that month. (NBS is computed as overlake precipitation and basin runoff less estimated lake evaporation.) Only the period of record preceding each month of 1995-August 1997 was used to assemble the sample for that month, simulating operation in real time. For example, for the first month of the period, January 1995, GLERL used all six-month NBS time series beginning in January, prior to 1995, to 
build a sample; for the thirtieth month of the period, June 1997, GLERL used all sixmonth NBS time series beginning in June, prior to 1997, to build a sample. GLERL then converted each sample of six-month NBS time series into a sample of six-month lake level scenarios with appropriate routing and regulation models; they used the resulting samples to infer a six-month probabilistic outlook of lake levels beginning each month of the period with the Weibull estimator. This operational hydrology forecast does not consider antecedent conditions or meteorological outlooks.

Secondly, GLERL simulated six-month lake level scenarios with their AHPS (which uses estimates of antecedent moisture and heat storage conditions with sixmonth pieces of the historical meteorological record). They did this for each month of the period 1995-August 1997 and assembled the six-month lake level scenarios into a sample for that month from which to estimate a six-month forecast beginning that month. Again, only historical meteorology preceding each forecast was used, simulating data availability in real time. Only provisional data were used, as they would have been available in near real time. Since no weightings were used, this represents forecasts, for each month of the period, that consider antecedent conditions but do not use meteorological outlooks.

Thirdly, GLERL simulated six-month lake level forecasts with their AHPS, using both antecedent conditions and NOAA's 1- and 3-month meteorological outlooks, for each month of the period. GLERL used ten methods for considering these meteorological outlooks in their hydrological outlooks. The first five methods used a mixture of simultaneous meteorological outlooks over seven lake basins and different objective functions to select among competing sets of weights. The second five methods used meteorological outlooks over each basin individually and different objective functions, as before, but defined only over each basin. Inspection of results revealed the best method for forecasting lake levels to be one that used a mixture of simultaneous meteorological outlooks over the seven lake basins and a minimization of the sum of squared differences between each weight and unity while using all nonzero weights. Actually, as will be revealed shortly, the meteorological outlooks added very little to the hydrological outlooks, and the manner in which the meteorological outlooks were used was not very significant. Thus the best method, just identified, is only marginally better than most of the other methods investigated. Only results for it are presented here since they are representative of the other methods.

All three of these operational hydrology methods yielded a set of six-month probabilistic lake level outlooks, which were simplified to yield a set of six-month deterministic outlooks for comparison to actual conditions. The simplifications consisted of taking the mean, the median, the mid-range between the 5\% and $95 \%$ quantiles, the mid-range between the $20 \%$ and $80 \%$ quantiles, and the mode (assuming a log-Pearson Type III distribution). There were little differences between uses of the various combinations, but the mean consistently gave the better results. Only results for it are presented here since it is representative of the other combination methods. GLERL then compared each deterministic forecast with what actually occurred to find the effects of considering antecedent moisture and heat storage conditions and considering meteorological outlooks. 
GLERL compared forecast monthly means and actual monthly average levels by using root mean square error (RMSE), bias, and sample correlation. Forecasts were also compared to climatology (monthly-means from the historical record), used as a reference forecast, against which more sophisticated forecast methods can be compared. A skill measure was developed as the average absolute difference between forecast and observed levels weighted by the normalized departure from climatology. RMSE and skill are measures of the absolute differences between forecast and actual values; low values of each of these measures indicate better performance. Skill is weighted to reflect the differences at extreme values more than differences near normal values. Bias is a measure of the shift between the distributions of forecast and actual values. Correlation is a measure of how well the timing of variability is captured by the forecast method.

More recently, GLERL updated all data sets and repeated all of these calculations in a second evaluation to take advantage of the additional data available for August 1997-2000. Results were similar and are not shown here. Likewise, results are shown here only for Lake Superior; other Great Lakes results are similar.

Finally, GLERL compared forecast and actual values in a probabilistic sense. There were too little data for evaluating the probabilistic outlooks with much confidence; grouping all first-month forecasts, regardless of their time-of-year, allowed building larger samples and evaluating forecasts probabilistically. This was repeated for second- through sixth-month forecasts too.

Component Error Evaluation. There is significant improvement when forecasting NBS directly from current antecedent conditions each month instead of using historical NBS in the straightforward operational hydrology approach. The RMSE on the left in the first (top) row of Figure 7 reveals this. This is more apparent in the correlation plot on the left in the second row of Figure 7. However, there appears to be very little improvement in the forecasts by considering available meteorological outlooks as far as RMSE and correlation are concerned. There is very little difference in forecasting (with antecedent conditions) either with or without meteorological outlooks. In fact, there are times when the use of meteorological outlooks slightly degrades RMSE and correlation. However, skill (which measures the ability to forecast non-central levels) does show more improvement (lower values) when meteorological outlooks are used in the forecast, as shown on the left in the third row of Figure 7. Figure 7 demonstrates that improvements in forecasting resulting from considering antecedent conditions are much greater than those associated with using meteorological outlooks. In terms of bias, the differences are not large as seen on the left in the fourth row of Figure 7. The positive bias indicates that forecasts under-predict at all lags on all lakes in the 1995-August 1997 evaluation; since the bias is almost linear with lag, a near-constant bias exists in forecasting NBS for all forecast months. For the 1996-2000 evaluation (not shown), bias is much closer to zero on all lakes. 

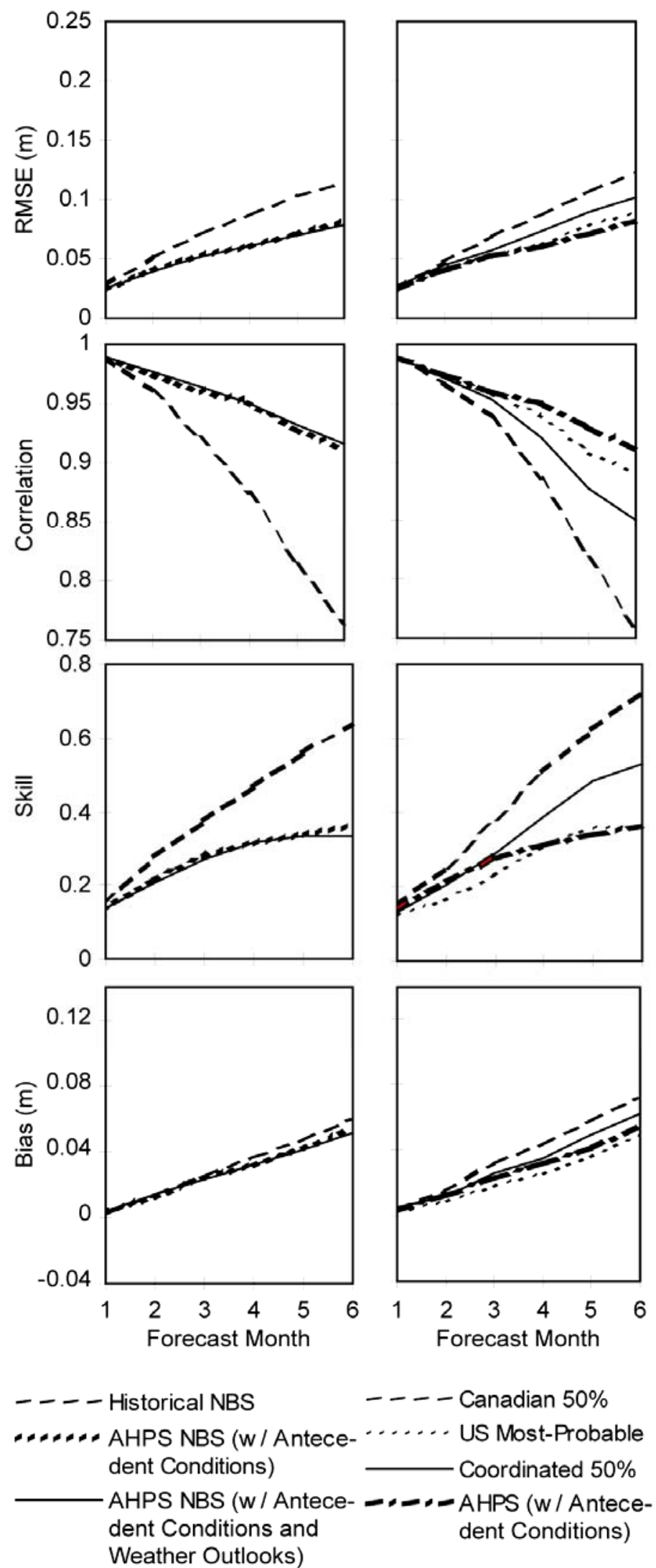

Figure 7. Lake Superior Water Level Forecast Evaluation for 1995-August 1997. 
Alternate Method Evaluation. In light of the small differences between the AHPS methodologies using meteorological outlooks and those not using them, only results for the latter are compared with other Great Lakes forecasts on the right side of Figure 7. Figure 7 shows that the AHPS forecast (which uses antecedent conditions, simply referred to henceforth as "AHPS forecast") has about the same (less than $1 \mathrm{~cm}$ difference) or smaller RMSE as the other forecasts. This is true on both Lakes Superior and Michigan-Huron for all lags, although it appears slightly better in the earlier evaluation. The US Most-Probable forecast is the next best on these lakes. In the earlier evaluation for Lake St. Clair, the two are about the same, and for Lake Erie the US Most-Probable has smaller RMSE. In the later evaluation, the AHPS forecast is close to or better than the other methods on Lakes St. Clair and Erie and better than the other methods on Lakes Superior and Michigan-Huron at higher lags only. The Canadian 50\% forecast has the largest RMSE in general and the Coordinated 50\% forecast RMSE lies between the Canadian 50\% and the US Most-Probable.

For yet another period, 1993-1995 (not shown), the AHPS forecast has about the same or smaller RMSE as the other forecasts on Lakes Superior, MichiganHuron, and St. Clair. On Lake Erie, it is second best only at two lags, but this time the Canadian 50\% forecast is better. The US Most-Probable forecast exhibits greater RMSE on Lakes Michigan-Huron, St. Clair, and Erie. Again the Coordinated 50\% forecast RMSE lies between the Canadian 50\% and the US Most-Probable. This suggests the AHPS forecast has consistently lower RMSE over different time periods than others.

The correlation associated with the AHPS forecast, in the 1995-August 1997 evaluation on the right in the second row of Figure 7, is uniformly and significantly higher for all lakes and all lags than the other forecasts. This suggests that the AHPS forecast best captures the timing of variations in lake levels. In the 1996-2000 evaluation (not shown), all forecasts are worse on Superior than in the earlier evaluation and the AHPS forecast is close to the US most-probable at some lags and better at higher lags. On Lake Michigan-Huron and Lake St. Clair, all methods are better in the later evaluation than in the earlier evaluation with the AHPS forecast better than the others at higher lags. On Lake Erie, the AHPS forecast has lower correlation in the later evaluation than in the earlier evaluation and the other methods are better in the later than in the earlier evaluations. However, the AHPS forecast still has the highest correlation in both.

Skill scores on the right in the third row of Figure 7 for the 1995-August 1997 period are generally the best for either the AHPS forecast or the US Most-Probable forecast. Skill scores are much closer for the 1996-2000 evaluation among all methods (not shown). However, for the 1993-1995 period (not shown), skill scores are generally the best for either the AHPS forecast or the Canadian $50 \%$ forecast. Surprisingly, the Coordinated 50\% forecast skill on Lakes St. Clair and Erie does not lie between the US and Canadian skills but is lower still for some lags. So, while the AHPS forecast is not uniformly better during the 1993-1995 period, the 1995-August 1997 period, or the 1996-2000 period, it is consistently better over all periods.

Bias on the right in the fourth row of Figure 7 for the 1995-August 1997 period is closest to zero for the US Most-Probable forecast and largest for the 
Canadian 50\% forecast. Both the Coordinated 50\% and the AHPS forecast biases are between them. For the 1996-2000 period, bias on Lakes Superior and MichiganHuron are closest to zero for the AHPS forecast, although improved for all methods over the earlier evaluation. For the 1993-1995 period (not shown), the AHPS forecast bias is also closest to zero on Lakes Superior and Erie. The Canadian 50\% dominates on Lake Michigan-Huron and the Coordinated 50\% dominates on Lake St. Clair. The US Most-Probable generally has the highest bias. So, while the AHPS forecast is not better on all lakes during all periods, it is more consistent than the other forecasts over the three periods. For any period, where the AHPS forecast bias is not close to zero, the forecast is positively biased (forecasts under predict), except for Michigan-Huron in 1996-2000. For the 1995-August 1997 period, the bias has an almost-linear trend with lag on all lakes, suggesting a near-constant bias exists in forecast AHPS for all forecast months of that period.

Probabilistic Comparisons. Although the period of comparison is very short for comparison of probabilistic forecasts (only two or three forecasts for each month of the year in the 1995-August 1997 period and only five forecasts for each month of the year in the 1996-2000 period), GLERL did compare the various forecasts probabilistically. By combining all first-month forecasts, regardless of month of the year, there are 32 values in the 1995-August 1997 period and 60 in the 1996-2000 period. Likewise there are 31 and 59 second-month forecasts respectively, 30 and 58 third-month forecasts respectively, and so on. Shown in Figure 8 on the abscissa are non-exceedance probabilities generated in the forecasts. The forecast lake level associated with each probability was compared to the actual lake level for each forecast; the fraction of actual levels at or below the forecast level are plotted on the ordinate for each forecast month. The dashed line represents a perfect probabilistic forecast. Also shown are the Coordinated 5\% \& 95\% non-exceedance levels.

On Superior, the AHPS forecast does better probabilistically than the Coordinated during the 1995-August 1997 evaluation, shown in Figure 8, for lags 1, $3,4,5$, and 6 (lags $2-6$ are not shown in Figure 8). Remember though that this is a small sample for comparison. Note, furthermore, that both methods consistently under-predict levels at longer lags, reflecting the increasing bias already observed (e.g., for the fourth month, the median forecast is not exceeded only about $30 \%$ of the time, or exceeded about $70 \%$ of the time). On Michigan (not shown), the AHPS forecast does better for the longer lags, 4 through 6 . On Lake St. Clair (not shown), the Coordinated $5 \%$ and $95 \%$ forecasts do better for all lags, but all are horrible! On Lake Erie (not shown), the Coordinated $5 \%$ and $95 \%$ forecasts do better for all lags except 6. For the 1996-2000 evaluation, the AHPS forecast looks better than in the earlier evaluation; it does not consistently under-predict levels at lags greater than one month. This is true for both Lakes Superior and Michigan-Huron. For Lakes St. Clair and Erie, the probabilistic comparisons are quite similar for both evaluation periods. The Coordinated forecast compares better to the AHPS forecast in the 19962000 period than it did in the 1995-August 1997 period but still the AHPS forecast comes closer to the ideal line more often. 

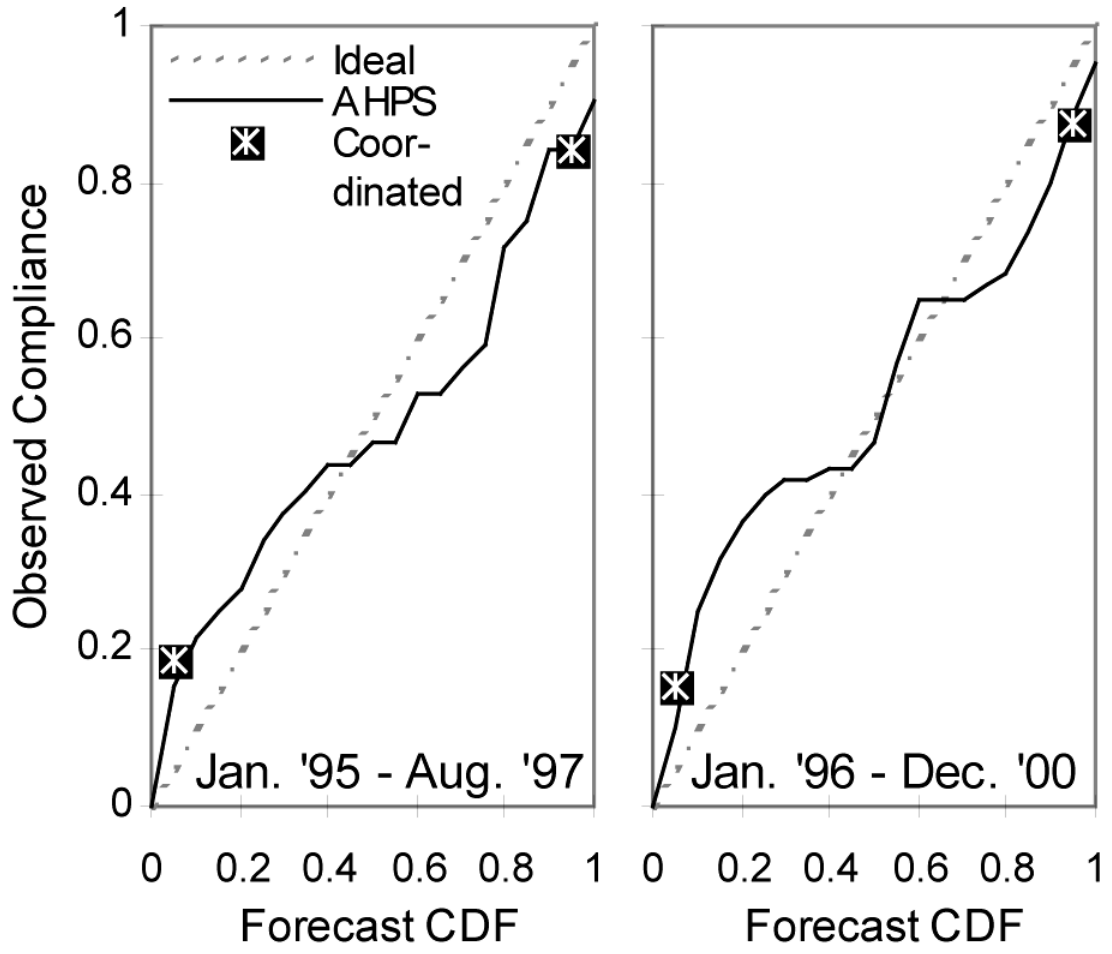

Figure 8. Lake Superior First-Month Forecast Probabilistic Comparisons

Evaluation Summary. The consideration of antecedent conditions greatly improves a forecast. Considering available meteorological outlooks generally improves estimation of extremes somewhat but has little effect overall; it may have more impact on a case-by-case basis. This is hardly surprising since the NOAA climate outlooks are known to lack skill in the Great Lakes area (Schneider and Garbrecht 2005). The AHPS forecast using antecedent conditions and meteorological outlooks generally has lower RMSE, higher correlation, better skill, and lower maximum error (not shown) than the US Most-Probable, the Canadian 50\%, and the Coordinated $50 \%$ forecasts of lake levels. This suggests that the AHPS forecast has generally the smallest differences with actual levels, best captures the timing of variations of lake levels, and is most-consistently best at the extremes over different periods. However, the AHPS forecast is often more biased than at least one of the other three during the early evaluation periods. This suggests that it is generally under-predicting slightly during those times of high levels (both 1993-1995 and 1995-August 1997), but the other forecasts are less consistent from period to period.

Although there are only six years of meteorological probability forecasts to assess, by combining all first-month forecasts into one sample, all second-month forecasts into another, and so on, it is possible to compare probabilistically. On Superior, the AHPS forecast more often is better than the Coordinated in both evaluation periods, especially in the 1995-August 1997 evaluation. Both the AHPS and the Coordinated forecasts appear to under predict at high levels for all forecast lags in both evaluation periods. Both over predict first-month low levels and under predict low levels at higher lags in the 1995-August 1997 evaluation. Probabilistic 
forecasting, in general, is better on Superior and Michigan-Huron than on St. Clair and Erie.

There are outside considerations affecting the evaluation. Both the Corps and EC use engineering judgment to adjust their actual forecasts, including alternate forecasts of NBS, their own use of GLERL's AHPS, experience with Superior regulation and mid-lakes routing, and precise knowledge of operating conditions (e.g., power plant capacities under existing head conditions at the time of a forecast and hence river flows at certain points). No doubt they can do better jobs of using GLERL's AHPS in actual practice than GLERL can. The 1993-1997 period represents above-normal lake levels and the 1996-2000 period represents belownormal lake levels, particularly in the latter part of the period. The improved performance of the US and Canadian forecasts, in the 1996-2000 evaluation relative to the 1995-August 1997 evaluation, may be due in part to the use of GLERL AHPS forecasts by the US and Canadian authorities (particularly the Detroit Corps) in making their outlooks during the 1996-2000 period. Furthermore, there are many details in the use of the Superior regulation plan and in the mid lakes routing that are glossed over with simple or antiquated assumptions in AHPS. These include rating equations, weed retardation coefficients, and ice retardation coefficients that are used in AHPS. Errors in routing make for differences with current practice. It should be possible to do a better job of simulating actual regulation and routing than AHPS does. This improvement awaits the final version of a Coordinated Great Lakes Routing and Regulation model (to determine Superior regulation and mid-lakes routing), currently being prepared by the Coordinating Committee on Great Lakes Basic Hydraulics and Hydrology Data.

\section{GREAT LAKES AHPS IMPACTS AND ASSESSMENT}

Capabilities of AHPS. GLERL's probabilistic hydrology outlooks are state-of-theart. They a) fully and correctly utilize the National Weather Service and Environment Canada probabilistic long range climate outlooks for multiple areas simultaneously, b) explicitly account for basin soil moisture and snow pack and lake heat storage and ice cover initial conditions, c) allow daily extended outlook generation, taking advantage of near-real-time data availability to offer continuously updated probabilistic outlooks, $\boldsymbol{d})$ utilize hydrology models in a modularly-built package that allows upgrades to be "dropped in" as developed and tested, $\boldsymbol{e}$ ) provide probabilistic outlooks for each lake and river watershed, capitalizing on improving weather prediction skill and hydrometeorology observations, $f$ ) offer the proper manner in which to consider the wide range of possibilities that always exist, $\boldsymbol{g}$ ) incorporate some of the uncertainty inherent in forecast estimates, and $\boldsymbol{h}$ ) allow consideration of risk by decision makers, as discussed subsequently. Comparisons show that even deterministic outlooks from the GLERL forecast package (constructed by simply averaging probabilistic outlooks) have higher skill than the Corps and Environment Canada outlooks.

Multiple Great Lakes Outlooks. Would an additional forecast available to the public cause confusion, especially since the US Army Corps of Engineers and Environment 
Canada both concurrently publish "coordinated" deterministic forecasts? The desire to see simply what the future will be cannot be accommodated, particularly for extended forecast periods. Instead, we must educate the public on how to process a range of possibilities through expression as probabilistic outlooks. GLERL's probabilistic hydrology outlooks provide additional information to the public, not contained in either the coordinated or component forecasts. The public can use the probabilistic information to assess risk at several different levels from simple (similar to TV weather forecasts) to more sophisticated (similar to existing probabilistic meteorology outlooks). These risk assessments may be associated with decisionmaking as shown in several Great Lakes case studies (Lee et al. 1997).

It behooves all parties to ease possible confusion by introducing GLERL's probabilistic outlooks along side of the current deterministic ones, with appropriate explanation on the interpretation and use of outlook probabilities. This would help to educate decision makers on using outlook probabilities to assess risk in their decision-making. This would also clarify the role of all of these outlooks in relation to one another. This is preferable to forcing users to wonder if the different outlooks, that they discover independently available, are conflicting or are related.

Responding To User Needs. There are several user groups in the Great Lakes community that make use of Great Lakes long-term water resource predictions of both hydrology and lake levels. These include lake navigation interests such as the Great Lake Carriers and their constituents who use water level forecasts to plan carrying capacity in ships based on available draft in connecting channels. These also include marina operators and other riparian businesses that must plan dredging needs during times of low water levels, or facility modifications during times of high water levels. Of course, regulation in the Great Lakes of Superior/Michigan-Huron water levels and of Ontario/St. Lawrence water levels considers hydrological forecasts. The consideration of hydrological forecasts in operation decisions may soon become even more important as the International Joint Commission finishes its 5-yr study, in a few more years, of Lake Ontario-St. Lawrence River regulation. Management of ice cover on the Great Lakes, for minimizing navigation impacts and ice-dam flooding effects, involves both the regulation of the lakes and the use of extended forecasts on the lakes. Municipal water utilities also make use of the forecasts in the management of their water intakes. Hydropower utilities use the forecasts in both supply and demand determinations. Finally, both of the official Great Lakes forecasting agencies in the US and Canada, the US Army Corps of Engineers (Detroit district) and Great Lakes - St. Lawrence Regulation Office of Environment Canada, use GLERL's AHPS as companion to their traditional techniques in an evaluation mode, to make and issue their monthly forecasts of extended Great Lakes hydrology and lake levels.

Probabilistic hydrology outlooks address NOAA's 1995-2000 Strategic Plan component for the enhancement of environmental prediction. The plan calls for an integrated environmental observation, assessment, and forecast service that supports the Nation's economic and environmental agenda both by significantly improving short-term (immediate to 60 days) forecasts, and by implementing reliable seasonal to interannual (60 days-10 years) forecasts. GLERL has been providing the short-term 
and seasonal service on the Great Lakes, in terms of water quantity, through its AHPS program for predicting Great Lakes hydrology variables since 1995 with subsequent improvements. The provision of annual and longer-term forecasts is not practical with present meteorology probability forecast skill. Longer-term hydrological outlooks are limited to running climate change scenarios determined from global circulation model experiments (Croley et al. 1996, 1998; Croley and Luukkonen 2003; Lofgren et al. 2002). Other NOAA offices (National Weather Service) have been providing both 1-2 day level outlooks (related to storm and wind setup) and 1week level outlooks on all Great Lakes. Studies that use this type of longer-term hydrological outlooks include the International Joint Commission's study of Lake Ontario-St. Lawrence River regulation. They are using selected 50-year climatechange scenarios of net basin supplies, generated through selected GCM simulations and interpreted through use of GLERL's AHPS, to assess the performance of candidate regulation plans and management strategies with respect to several user communities.

GLERL's probabilistic hydrology outlooks also address the recommendation of the International Joint Commission to the US and Canada as a result of their Levels Reference Study (IJC 1993), referred to in the Background section. The 5year study examined methods to alleviate problems associated with Great Lakes-St. Lawrence River Basin fluctuating water levels and outflows. They recommended development of improved lake operation and management tools, "[to] upgrade models used for simulation, forecasting and regulation in order to formulate a comprehensive water supply and routing model that includes the whole basin." In its report to the governments, the IJC supported the development of risk analysis techniques for application in management of water levels issues. The IJC recognized the usefulness of risk analysis in its work under the Great Lakes Water Quality Agreement and supported their extension to lake level management.

Example Risk Based Management. There is resistance to using probabilistic outlooks in decision-making, arising out of the lack of understanding of probability and risk, and out of reliance on familiar traditional decision-making techniques involving "yes-or-no" approaches based on deterministic lake level outlooks. The Corps is very sensitive to users of its outlooks who insist on knowing what (deterministic) lake levels are expected. On the other hand, several agencies are using GLERL's AHPS outlooks in risk-based decision making. An excellent example is the New York Power Authority (NYPA) who run the Niagara and St. Lawrence power plants, supplying $10 \%$ of New York's energy needs. Beginning in 1999, low water levels in the Great Lakes reduced the amount of hydroelectric generation delivered to NYPA's customers. Hydro generation was insufficient to meet customer loads by $20 \%$ in some months. Low water levels have cost NYPA hundreds of millions of dollars since 1999. Questions regarding the magnitude and persistence of the hydro shortfall are best answered by analysis of likely future scenarios. AHPS provides probabilistic hydrologic outlooks and is well suited to help answer these questions.

NYPA uses AHPS to make 50 extended flow-forecast sequences, each month of operation, which are assumed to be independent and equally likely to occur 
(unweighted to ignore climatic predictions). The Niagara River flow forecast ensemble can be translated into hydropower generation forecast ensembles, taking care to include flow-to-generation regression model errors. These sequences form an ensemble from which risk analysis can be performed. Two risk analysis examples follow.

One industrial customer that is largely dependent on a delivery of 200 megawatts of interruptible hydroelectric power has closed down a production line. The delivery of interruptible power can resume when hydro generation exceeds the critical threshold of 2,250 megawatts. The customer and NYPA wants to know the probability that interruptible power can be delivered in upcoming months. An analysis of the ensemble indicates that the probability of delivering interruptible power in any one month does not exceed 50\% until 2005.

Since January 2000, NYPA has been forecasting the amount of generation that is insufficient to meet customer loads for the upcoming month. If it turns out that the actual shortfall was more severe than forecasted, NYPA bears the additional cost for supplemental power rather than passing this cost along to the customer. For the upcoming forecast month, NYPA wants to know the probability that generation will be insufficient to meet the customer load and the probability of bearing this additional cost and the magnitude of this cost. Answers to these questions can be extracted from the ensemble.

Uncertainty in hydropower generation, fossil-fuel power generation, and market prices can be used to develop decision models for hydropower plant operation. The Northbridge Group is developing a business decision model that will guide operation of pumped storage power plants based upon market price triggers. For example, when the forecast market price exceeds a trigger price, the pumped storage plant will generate electricity. Likewise, when the forecast market price is lower than a trigger price, the plant will buy electricity to pump water into storage.

\section{ACKNOWLEDGMENTS}

The author thanks Rich Mueller of New York Power Authority for the above example. This is GLERL contribution number 1291.

\section{REFERENCES}

Croley, T. E., II. (1989). Verifiable evaporation modeling on the Laurentian Great Lakes. Water Resources Res., AGU, 25(5):781-792.

Croley, T. E., II. (1992). Long-term heat storage in the Great Lakes. Water Resources Res., AGU, 28(1):69-81.

Croley, T. E., II. (2000). Using Meteorology Probability Forecasts in Operational Hydrology. ASCE Press, American Society of Civil Engineers, Reston, Va., 214 pp. 
Croley, T. E., II. (2002). Large basin runoff model. In Mathematical Models in Watershed Hydrology (V. Singh, D. Frevert, and S. Meyer, Eds.), Water Resources Publications, Littleton, Colorado, 717-770.

Croley, T. E., II, and R. A. Assel. (1994). A one-dimensional ice thermodynamics model for the Laurentian Great Lakes. Water Resources Res., AGU, 30(3):625-639.

Croley, T. E., II, and H.C. Hartmann. (1985). Resolving Thiessen polygons. J. Hydrology, AGU, 76:363-379.

Croley, T. E., II, and C. L. Luukkonen. (2003). Potential climate change impacts on Lansing, Michigan ground water. J. Am. Water Resources Assoc., 39(1): 149-163.

Croley, T. E., II, Quinn, F. H., Kunkel, K. E., and S.A. Changnon. (1996). Climate transposition effects on the Great Lakes hydrological cycle. NOAA Tech. Memo. ERL GLERL-89, Great Lakes Environmental Research Laboratory, Ann Arbor, 100 pp.

Croley, T. E., II, F. H. Quinn, K. E., Kunkel, and S. J. Changnon. (1998). Great Lakes hydrology under transposed climates, Climatic Change, 38:405-433.

Hartmann, H. C. (1987). An evaluation of Great Lakes hydraulic routing models. NOAA Tech. Memo. ERL GLERL-66, Great Lakes Environmental Research Laboratory, Ann Arbor, 9 pp.

Hartmann, H. C. (1988). Historical basis for limit on Lake Superior water level regulations. J. Great Lakes Res., 14(3):316-324.

International Great Lakes Diversions and Consumptives Uses Study Board. (1981). Great Lakes Diversions and Consumptive Uses. International Joint Commission, Washington, D. C.

International Joint Commission. (1993). Methods of Alleviating the Adverse Consequences of Fluctuating Water Levels in the Great Lakes-St. Lawrence River Basin. Report to the Governments of Canada and the United States. International Joint Commission, Washington, D.C. and Ottawa, Ontario, Canada.

International St. Lawrence River Board of Control. (1963). Regulation of Lake Ontario: Plan 1958-D., Washington, D. C.

Lee, D. H., A. H. Clites and J. P. Keillor. (1997). Assessing risk in operational decisions using Great Lakes probabilistic water level forecasts, Environ. Manag., 21(1):43-58.

Lofgren, B. M, F. H. Quinn, A. H. Clites, R. A. Assel, A. J. Eberhardt, and C. L. Luukkonen. (2002). Evaluation of potential impacts on Great Lakes water resources based on climate scenarios of two GCMs. J. Great Lakes Res., 28(4):537-554. 
Quinn, F. H. (1978). Hydrologic response model of the North American Great Lakes. J. Hyd., 37:295-307.

Quinn, F. H. (1982). Trends and extremes of Lake Erie water supplies. Proc. International Symposium on Hydrometeorology, American Water Resources Association, Minneapolis, 267-270.

Quinn, F. H. (1985). Great Lakes water levels. In Great Lakes Water Levels, Briefing of Senators and Representatives from the Great Lakes Basin July 19, International Joint Commission, Washington, 1-24.

Quinn, F. H., and T. E. Croley II. (1981). The role of precipitation climatology in hydrologic design and planning on the Laurentian Great Lakes. Proc. Fourth Conference on Hydrometeorology, American Meteorological Society, Boston, 218223.

Quinn, F. H., and R. N. Kelley. (1983). Great Lakes monthly hydrologic data. NOAA Technical Memorandum ERL GLERL-39, National Technical Information Service, Springfield.

Schneider, J. M. , and J. D. Garbrecht. (2005). Utility of Recent NOAA/CPC forecasts of Seasonal Precipitation, this volume. 


\title{
Climate Variations, Climate Change, and \\ Water Resources Engineering
}

\author{
SPONSORED BY \\ Environmental and Water Resources Institute (EWRI) \\ Of the American Society of Civil Engineers \\ Surface Water Hydrology Committee
}

\author{
EDITED BY \\ Jürgen D. Garbrecht \\ Thomas C. Piechota
}

Published by the American Society of Civil Engineers 


\section{Table of Contents}

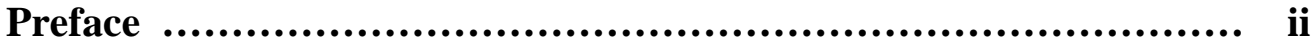

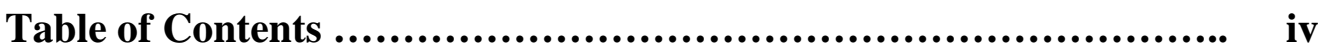

Part I: An Overview

Climate Variability and Climate Change

2

T. C. Piechota, J. D. Garbrecht, and J. M. Schneider

Water Resources and Climate

18

J. D. Garbrecht and T. C. Piechota

\section{Part II: Case Applications}

Decade-Long Precipitation Variations and Water Resources

Management

J. G. Garbrecht, J. M. Schneider, and G. O. Brown

Recent Utility of NOAA/CPC Seasonal Precipitation

Climate Forecasts

J.. M. Schneider and J. D. Garbrecht

Application of Climate Outlooks for Water Management

in South Florida

P. Trimble, J. Obeysekera, L. Cadavid, and E. R. Santee

Integration of Climate Information and Forecasts into

Western US Water Supply Forecasts

T. C. Paganao and D. C. Garen

Teleconnections and Disconnections in Central Texas: A Guide for Water Managers

D. W. Watkins, Jr. and S. M. O'Connell

Acclimatizing Water Managers to Using Climate Forecasts

C. K. Baldwin, M. D. Waage, and R. G. Steger

Climate Variability, Water Supply, and Drought in the Upper Colorado River Basin 
Climate Variability and Impacts on Irrigation Water Demand:

Research and Application in Northeast Florida ......................

J. M. Jacobs, S. R. Satti, M. D. Dukes and J. W. Jones

Global Warming: Assessing Hydrology on Regional and

Smaller Scales

B. M. Lofgren

Great Lakes Advanced Hydrologic Prediction System

T. E. Croley II 
